Jialong Jiao

Shuzheng Sun

Huilong Ren

http://dx.doi.org/10.21278/brod201667206

ISSN 0007-215X

eISSN 1845-5859

\title{
PREDICTIONS OF WAVE INDUCED SHIP MOTIONS AND LOADS BY LARGE-SCALE MODEL MEASUREMENT AT SEA AND NUMERICAL ANALYSIS
}

UDC 629.5(05) 629.5.017.2:629.5.018:519.61

Original scientific paper

\begin{abstract}
Summary
In order to accurately predict wave induced motions and load responses of ships, a new experimental methodology is proposed. The new method includes conducting tests with largescale models under natural environment conditions. The testing technique for large-scale model measurements proposed is quite applicable and general to a wide range of standard hydrodynamic experiments in naval architecture. For the needs of this study, a large-scale segmented self-propelled model was designed for investigating seakeeping performance and wave load behavior and for testing the systems, and relevant experiments were performed. A two-hour voyage trial of the large-scale model in order to perform a series of simulation exercises was carried out at Huludao harbor in October 2014. During the voyage, onboard systems, operated by the crew, were used to measure and record the sea waves and the model responses. The post-voyage analysis of the measurements, both of the sea waves and the model's responses, was made to predict the ship's motion and load responses of short-term at the corresponding sea state. Furthermore, the numerical analysis of the short-term prediction was made using an in-house code and the result was compared with the experiment data. The long-term extreme prediction of motions and loads was also carried out based on the numerical results of the short-term prediction.
\end{abstract}

Keywords: $\quad$ wave load; hydroelasticity; seakeeping performance; large-scale model; sea trial; coastal waves

\section{Introduction}

Accurate prediction of wave induced ship motions, hydrodynamic loads and the resulting structural response is of crucial importance in ship preliminary and contract design. For example, the design of the hull shape is mainly based on the prediction of seakeeping and resistance behavior during the navigational lifetime. Moreover, the structural design of ships 
depends on loads predicted by experimental or numerical methods, and the strength of the hull structure should neither be overestimated nor underestimated for the sake of both economic and safety factors.

Generally speaking, there are basically two different approaches of calculating the motions and load responses of a ship: rule book approach and direct calculation [1-2]. Although the former is quite convenient at the preliminary design stage, one cannot easily obtain an optimal design for a specific ship. The latter approach seems to be a better choice than the former one in such cases. However, since the numerical problems involving the interaction of a moving irregular body with a fluid in the presence of free surface are quite complicated, tests are still indispensable for the fields of naval architecture and shipbuilding. Experimental studies do not only reliably reflect what happens on the ship, but are also used to validate the numerical results. However, there are also challenges regarding experimental studies. For example, the time and cost consumed in fabrication and performing experiments are much higher than those in numerical simulation.

The majority of ship hydrodynamic tests are carried out in towing tanks using smallscale ship models. The scaled ship models are towed in still water or in uni-directional, artificially generated, pseudo-random waves [3]. On the other hand, full-scale sea trials are believed to provide the most reliable and realistic data with respect to ship behavior in various environments. Therefore, more and more commercial and military ships are equipped with permanent monitoring systems to record the ship's operational data and responses to the current environment for the up-to-date decision making and long-term improvements to design and simulation tools. However, the cost and the time consumed for sea trials are tremendous. The extreme harsh sea conditions would be a huge threat for the crew and the ship [4-6], which makes it not a universal method for ship design and hydrodynamic investigation.

In order to address the issues imposed by the small-scale and full-scale testing methods, large-scale ship model tests are conducted in natural environment conditions. The models are usually designed as self-propelled and radio-controlled. This methodology offers many advantages, such as reductions of scale effects and the suppression of any speed or other limitations associated with the specifications of the towing carriage and tank size. More importantly, the sea waves the model encounters are wind-generated short-crested nonlinear waves.

In some European countries, measurement techniques for large-scale models in natural environment conditions have been developed in the past decade [7-10]. However, because of their high superiority, the present technical papers are, for the sake of confidentiality, limited to report model photos or introductory materials. In the year 2007, the Ship Environmental Adaptability Research Centre of Harbin Engineering University performed large-scale measurements at sea for the seakeeping performance and hull optimization of two novel ships. This was the first step of testing large-scale model's hydrodynamic behavior in the natural wave environment in China. The testing models are about $7 \mathrm{~m}$ long with a scale ratio of 1:19. The detailed information about the measurements is given in [11-12]. With some problems encountered during the first-year trials, such as the power and communication systems not being steady enough, the second trials in the year 2009 were aimed at improving the testing systems by introducing new instruments onboard the model. The second-year results turned out to be much better than the first-year's [13]. However, in the authors' previous researches the ships were designed as rigid hulls, which could not reflect the elastic effects of ship girders. Furthermore, according to the authors' best knowledge, so far, there has been very little published literature related to the wave loads experiments performed using a large-scale segmented model in coastal sea [14-15]. 
In this study, a segmented self-propelled large-scale model for the investigation of wave loads behavior and seakeeping performance in coastal waves is presented. First, the model design and experimental procedures are presented. A 2-hour voyage trial performed at Huludao harbor proves that the proposed testing systems are reliable. Then, the examples of experimental results, including the sea waves measured and the model's motion and load response results are reported and analyzed by spectral method. Next, a comparative analysis of short-term extreme values between the experiment data and the statistical model results is made. Lastly, numerical simulations for both short-term and long-term predictions are made using an in-house code.

\section{Design of experimental campaign}

\subsection{Model design}

In order to investigate wave induced motions and load responses of a large-scale model at sea, a fiberglass-reinforced plastics segmented hull model with a steel backbone at its neutral axis was made with a scale ratio of 1:25. The model parameters are given in Table 1 . In the table, VCG and LCG denote vertical and longitudinal centre of gravity (COG), respectively. BL denotes baseline, and AP denotes after perpendicular. $K_{x x}$ and $K_{y y}$ denote transverse and longitudinal radius of gyration respectively. Where $K_{x x}$ and $K_{y y}$ are determined by the knowledge of seakeeping performance using the empirical formulas as follows:

$$
\begin{aligned}
& K_{x x}=0.35 B \\
& K_{y y}=0.25 L
\end{aligned}
$$

where $B$ denotes moulded breadth, $L$ denotes length overall.

Table 1 Main dimensions

\begin{tabular}{|c|c|c|}
\hline Principal dimension & Ship prototype & $\begin{array}{c}\text { Large-scale } \\
\text { model }\end{array}$ \\
\hline Scale & $1 / 1$ & $1 / 25$ \\
\hline Length overall [m] & 313 & 12.52 \\
\hline Length waterline [m] & 292 & 11.68 \\
\hline Moulded breadth [m] & 39.5 & 1.58 \\
\hline Depth [m] & 25.5 & 1.02 \\
\hline Draft [m] & 10 & 0.40 \\
\hline Displacement [t] & 71875 & 4.6 \\
\hline VCG from BL [m] & 16 & 0.64 \\
\hline LCG from AP [m] & 140.5 & 5.62 \\
\hline$K_{x x}[\mathrm{~m}]$ & 13.83 & 0.553 \\
\hline$K_{y y}[\mathrm{~m}]$ & 78.25 & 3.13 \\
\hline
\end{tabular}

The ship model was designed with 20 sections and was divided into seven segments by using the 2nd, 4th, 6th, 8th, 10th and 12th parts. The segmented hulls are connected by the backbone model. The segmented hulls are used to transfer the hydrodynamic loads experienced by the hulls to the backbone. The gaps between each two segmented hulls are provided to prevent mutual touching of the segmented hulls during the deformation of the backbone model in waves. The gaps are sealed by using latex rubber, which is watertight and elastomeric. Wave loads at the 2nd, 4th, 6th, 8th, 10th and 12th divisions, i.e. the sections between the segments, were measured by full-bridge strain gauges placed on the backbone. 
The monolithic large space at the stern, which has, is used for installing the propulsion system between the $13^{\text {th }}$ and $20^{\text {th }}$ sections. The secondary level deck above the backbone model is used for the placement and fixing of all the testing equipment, batteries and iron blocks. The mass distribution and radii of gyration of the model are designed to be similar with the ship prototype, which is achieved by proper arrangement of all the components onboard the model following the calculation result. It is worthy to clarify that the superstructure of the model is not the realistic one. However, it is a simplified design of equivalent wind area with repect to real condition. A photo of the model before being launched into sea is shown in Figure 1(a). The photo of the backbone system is shown in Figure 1(b), which was taken after assembly of the segmented hulls in the laboratory. The view of onboard testing systems is presented in Figure 1(c). The propulsion system, which includes four screw propellers and twin rudders, is shown in Figure 1(d).

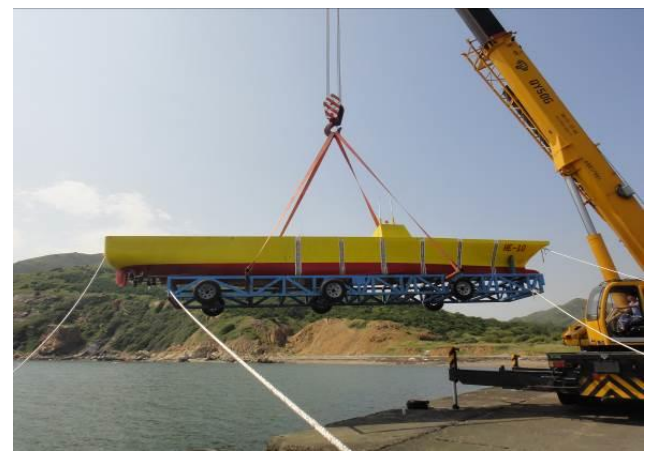

(a) Model hull

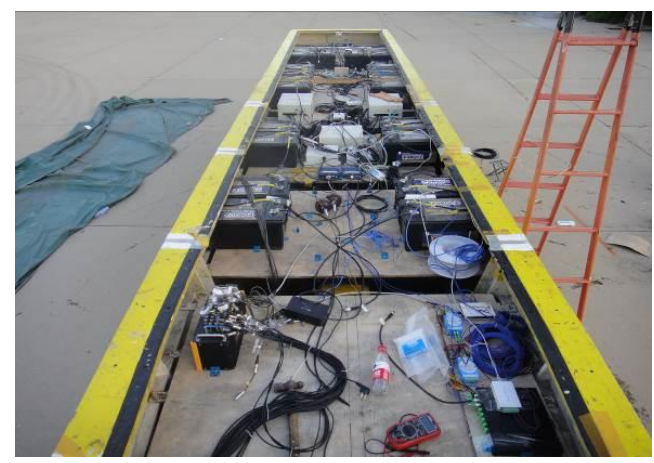

(c) Model equipment and batteries

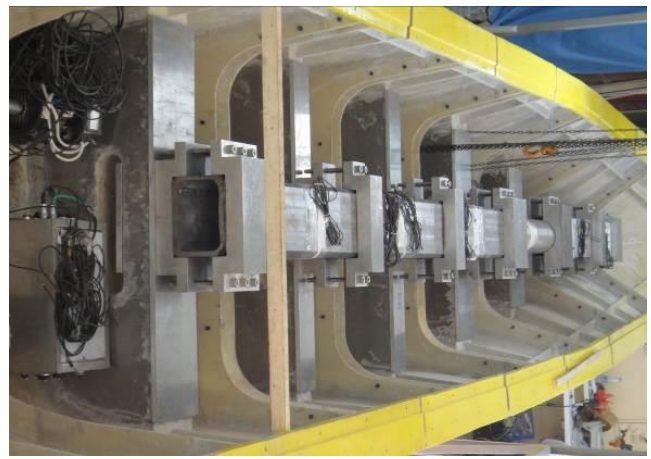

(b) Backbone system

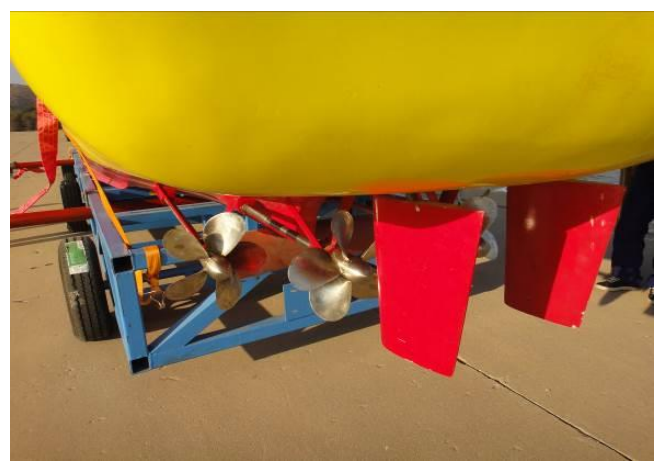

(d) Screw propellers and rudders

Figure 1 Photos of the large-scale model ship

\subsection{Testing systems}

The testing systems and the platform are of central importance for the experimental measurements. During the tests, the model works with the assistance of a workboat. The crew onboard the auxiliary workboat operates the model ship by radio to control that it runs as desired. The self-propelled unmanned model is equipped with all the technical devices necessary to carry out the experimental activities. These are described below.

(1) GPS/INS device

GPS/INS device is used to measure and record simultaneously the information on the ship model's speed, position, and motions. Two GPS receivers are positioned on the ship's deck centerline, with one being positioned forward and the other one aft. Data sampled by the GPS/INS core unit at the COG of the model are transmitted to the auxiliary workboat via radio signal, and then processed in the laptop and exhibited to the crew. The interface for the model's detailed navigational information is shown in Figure 2. 


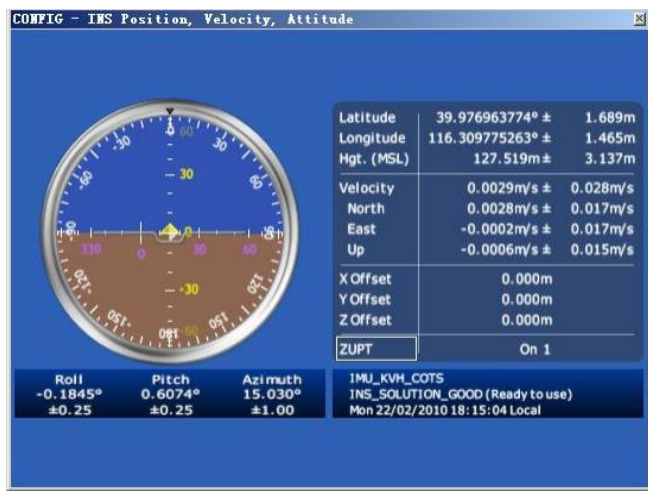

(a) Sailing information

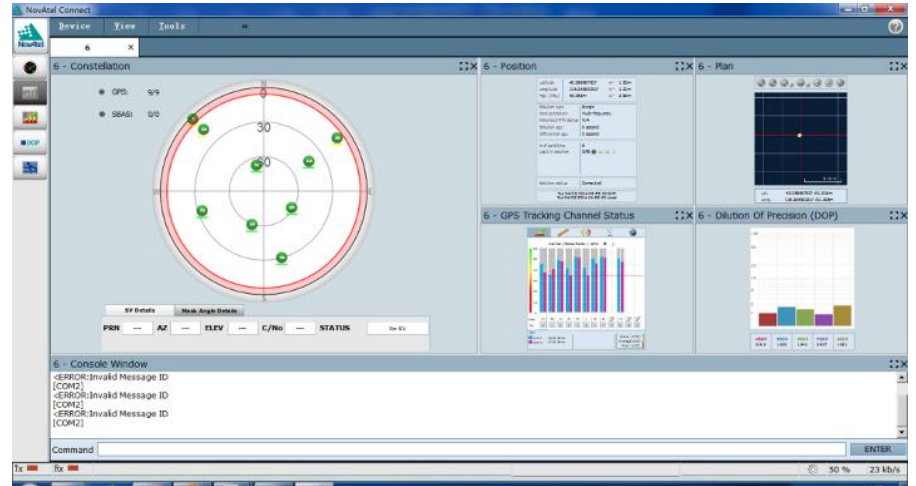

(b) Static debugging

Figure 2 Interface of model's navigation information

(2) Model control system

In order to achieve testing schemes of different speeds and heading angles, a remote control system, whose working principle is shown in Figure 3, was developed. The model's velocities and heading are shown on the interface in the auxiliary workboat. Inputs were done on the GPS/INS device to change the model speed or course.

The design speed of the ship prototype in an ordinary sea state is 18 knots, which corresponds to the model speed of $1.852 \mathrm{~m} / \mathrm{s}$. In an extremely sea state, the sailing speed is 5 knots, corresponding to the model speed of $0.514 \mathrm{~m} / \mathrm{s}$. The maximum speed of the ship prototype is designed as 24 knots, corresponding to $2.469 \mathrm{~m} / \mathrm{s}$ of the model speed. Model resistance performance was calculated by the Fluent software and propellers thrust was checked by an empirical design method so that the model could be competent for all the testing schemes even in harsh seas.

Since motor revs are proportional to the exciting voltage, sailing speed regulation is realized by modifying the value of the exciting voltage. The control computer on the auxiliary workboat is used to enter the values of exciting voltage that would then transmit a voltage signal via the radio to the control box on the model ship. The signal entered into the control computer varies from 0 to $5000 \mathrm{mV}$. A value of $5000 \mathrm{mV}$ is corresponding to the largest sailing speed of the model ship.

The twin rudders of the large-scale ship model are steered by an autopilot system, which is a commercial production of GARMIN Company. The autopilot system mainly comprises four components: the electronic control unit, the course computer unit, the user control interface, and the drive unit. The autopilot system controller, supported by a GPS-unit, is based on PID control algorithm. A course top is introduced to feedback the sailing course in real time. The hydraulic drive unit controls the angle of the rudders to keep or change course. The autopilot system takes care of the route of the model, and the only thing the steersman needs to do is to set or regulate the course through the user's control interface.

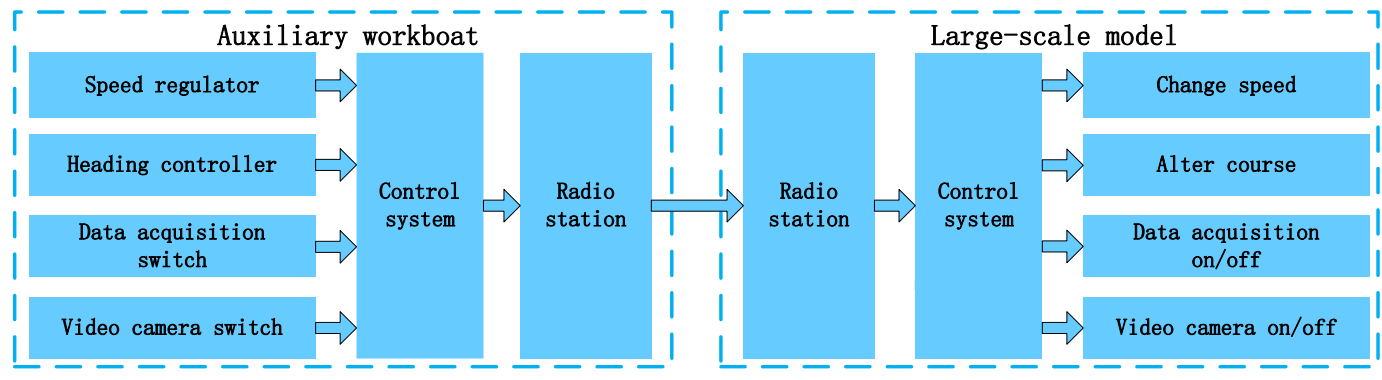

Figure 3 Framework of the remote control system 


\section{(3) Data acquisition system}

DH5902 data acquisition system produced by DONGHUA Test Technology Company was adopted for the measurements. The measured data are recorded on its hard disk and the power is provided by a rechargeable battery. The start or stop of data acquiring is controlled by the pulse signal transmitted from the auxiliary workboat via radio, as can be seen in Figure 3.

The main objective of the measurement was to measure the hull girder sectional vertical bending moment (VBM) in waves. In addition, ship motions, accelerations, slamming pressures and sea waves were measured. Vertical bending moments were measured by full bridge strain gauges placed on the backbone model. The typical data recorded by the GPS/INS device at the COG of the model during navigation were: ship trajectory, absolute speed, pitch, and roll. The vertical accelerations at the model bow 1st station, the amidships 10th station, and the stern 19th station were measured by accelerometers. The sampling frequency of strain gauges and accelerometers was set at $100 \mathrm{~Hz}$ in this measurement.

Fourteen pressure sensors were disposed at the bow of the ship to measure the bottom slamming and flare impact pressure. The pressure sensors had a range from -0.1 to $1.0 \mathrm{MPa}$ and a measurement accuracy of $\pm 0.25 \% \mathrm{FS}$ (full scale). The input voltage was $\pm 15 \mathrm{~V}$ DC and the working temperature ranged from -20 to 80 degrees centigrade. The arrangement of the gauges on the model is shown in Figure 4(a) and a photo of a pressure gauge is shown in Figure 4(b). Generally speaking, the sampling frequency of the pressure sensors should be set not less than $1000 \mathrm{~Hz}$ for model tests. However, the data acquisition system worked for several hours continuously during the sea trial. In order to save the data storage memory, we chose the frequency of $100 \mathrm{~Hz}$ in this measurement, which is a compromise between the testing requirement and the available storage memory. Moreover, the main purpose for this paper was to study the load and motion responses of the model rather than the pressure response.

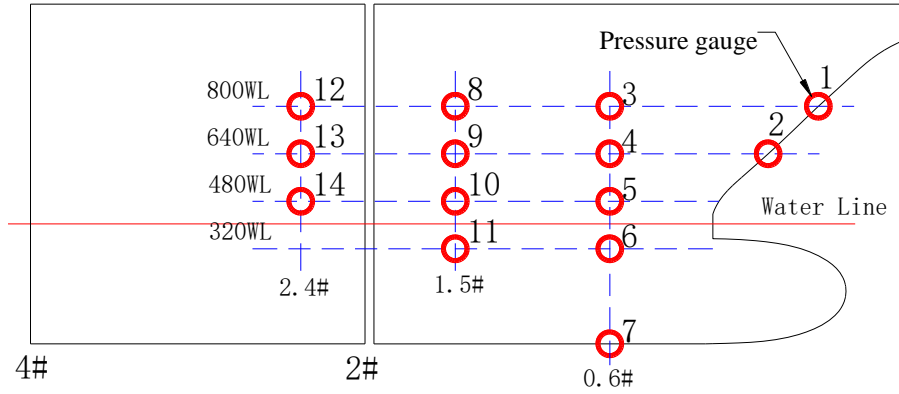

(a) Arrangement of pressure gauges

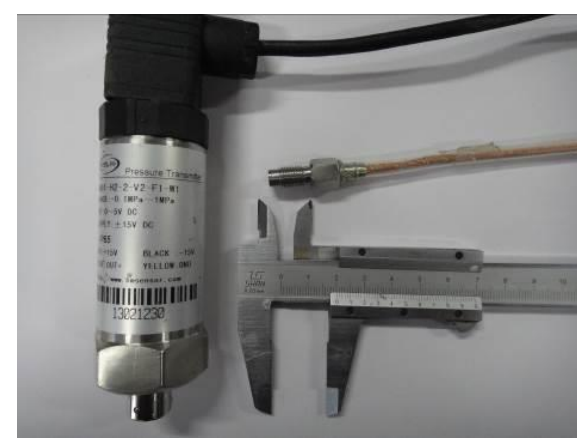

(b) View of a pressure gauge

Figure 4 Description of pressure measurements

\section{(4) Wave measurement system}

A spherical buoy wave height meter, with an iron chain fitted at its bottom to lower the barycentre, was used for sea wave measurement. It had an accelerometer fitted near its COG to measure the instantaneous acceleration of wave surface elevation. The lower part of the buoy was immersed in water, and there was a spoiling flap in the middle of the buoy to reduce the swing motion. As it is light enough, about $35 \mathrm{~kg}$, it was easy to transport, deploy and retrieve it from the auxiliary workboat by the two-person crew. Instantaneous acceleration data were acquired automatically at preset intervals or on demand. After acquisition and onboard processing, wave data could be downloaded via a UHF radio modem or a hardwire connection upon retrieval. The frequency for data acquisition was set at $50 \mathrm{~Hz}$ in the 
measurement, and each collecting time lasted about 10 minutes at a given location. The buoy wave height meter was located at different places for different measurements in the testing area so as to ensure that sea waves sampled were consistent with those acting on the model.

\subsection{Trial arrangement}

An exploratory large-scale model measurement was performed at Huludao harbor (GPS coordinate long. $40^{\circ} 69^{\prime}$, lat. $120^{\circ} 91^{\prime}$ ) of China in October 2014. The sea bay is large enough to allow the execution of any kind of hydrodynamic tests. The channel is well sheltered from the prevailing swell. For the model leaving the coast, the measurements were taken approximately $4 \sim 5 \mathrm{~km}$ southeast of the beach. During the measurement, winds blew from open seas towards the coast. Figure 5 shows the testing field and the voyage route for the trial. The trial was intended to act as a series of simulation exercises, which lasted about 2 hours.

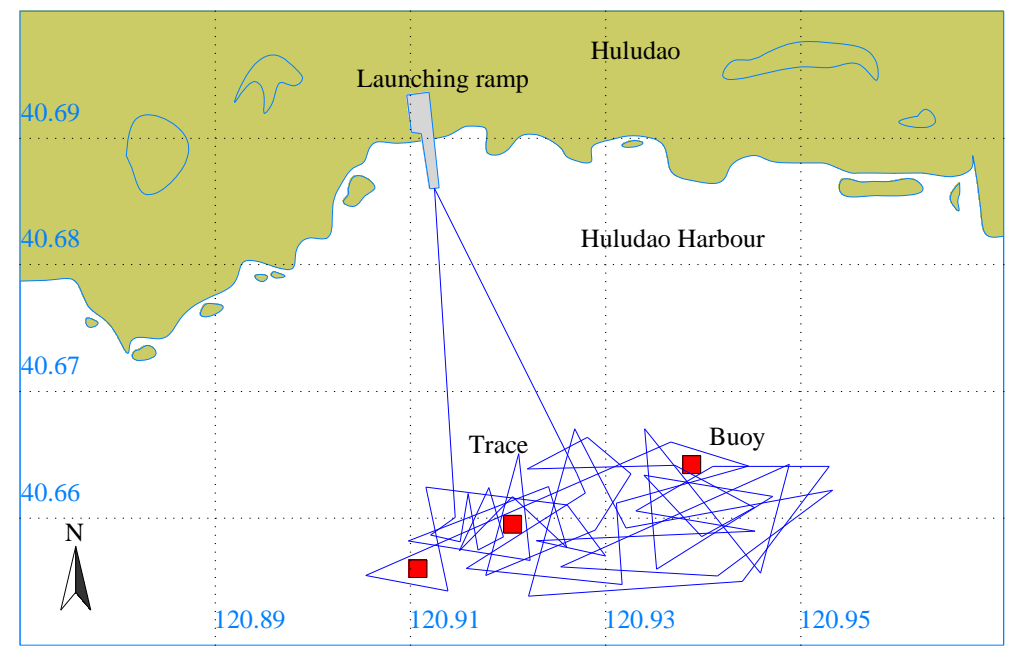

Figure 5 Voyage map of the sea trial

During the tests, the crew on the auxiliary workboat controlled the model to make it run at a given speed and course. Meanwhile, the buoy meter measured the sea waves. Typically the model would be in a radius of $1 \mathrm{~km}$ and occasionally up to $2 \mathrm{~km}$ from the buoy during the trials. Two cameras, one was supported by the crew onboard the auxiliary boat and the other one mounted onboard the model deck, recorded the tests simultaneously. All the testing crew earnestly cooperated in order to ensure the experimental platform system operating in a perfect condition, thus the measurements could proceed smoothly and successfully. It was important to have no interruptions in any of the model's operations.

\section{Testing results}

\subsection{Analysis of coastal waves}

During the sea trial, three measurements of the sea waves were taken at different locations and different times by the buoy, as shown in Figure 5. The main direction of the wave propagation was the same as that of the generating wind direction, which was from the SSE during the measurements.

In order to visualize the composition of the wave energy in terms of significant wave heights and characteristic periods, the correlation function of the acceleration is derived as follows:

$$
R(\tau)=\lim _{T \rightarrow \infty} \frac{1}{T} \int_{0}^{T} \ddot{\zeta}(t) \cdot \ddot{\zeta}(t+\tau) d t
$$


where, $\tau$ is time interval, and $T$ is duration of the measured data.

Then the Fourier transform of the formula above is carried out, from which spectral density function of wave surface vertical acceleration is derived as follows:

$$
S_{\ddot{\zeta}}(\omega)=\frac{2}{\pi} \int_{0}^{\infty} R(\tau) \cos \omega \tau d \tau
$$

The wave spectrum density of free surface elevation is derived by two quadratures of the acceleration spectrum using the formula:

$$
S_{\zeta}(\omega)=S_{\zeta}(\omega) / \omega^{4}
$$

Then the significant wave height $H_{1 / 3}$ and characteristic period $T_{z}$ are calculated as follows:

$$
\begin{aligned}
& H_{1 / 3}=4 \sqrt{m_{0}} \\
& T_{z}=2 \pi \sqrt{m_{0} / m_{2}}
\end{aligned}
$$

where, $m_{n}$ denotes the $n$th order moment of the estimated spectrum density function.

The coastal waves in sheltered water are definitely slightly different from deep-ocean waves due to shoaling, diffraction, refraction, and breaking of waves. In order to investigate further whether the nearshore waves in sheltered waters at Huludao harbor are similar to the deep-ocean's, a comparative study between the measured nearshore wave spectra and the ISSC double parameters spectrum of dimensionless form was carried out. In the dimensionless spectral analysis [16], spectral density is usually adopted as $S(\omega) \cdot \omega_{m} / m_{0}$, where $\omega_{m}$ denotes the spectral peak frequency. The spectral analysis results of the three measurements data were compared with the ISSC dimensionless double parametric spectrum of and the result is shown in Figure 6. The significant wave heights and the corresponding characteristic periods obtained by the above-mentioned spectral method for the three measurements are $0.561 \mathrm{~m}$ and $3.267 \mathrm{~s}, 0.584 \mathrm{~m}$ and $3.013 \mathrm{~s}$, and $0.570 \mathrm{~m}$ and $3.296 \mathrm{~s}$, respectively. The wind and the waves were steady enough during the testing period, so it is reasonable to believe that all the testing schemes reported in this paper were carried out under the average sea state measured.

The agreement of the spectra in Figure 6 is tested by the average variance of the curves, and formula is expressed as follows:

$$
\sum_{i=1}^{n}\left[S_{\zeta}(i \omega)-S_{\zeta}^{\prime}(i \omega)\right]^{2} / n \leq 0.03
$$

where, $S_{\xi}(i \omega)$ denotes the value of scattered points in the dimensionless spectral result, $S_{\xi}(i \omega)$ denotes the value of target spectrum of corresponding frequency, $n$ denotes the total number of scattered points in the $95 \%$ dominant energy range. The average variances of the three measurements are $0.017,0.011$ and 0.009 , respectively. This shows that the waves the model encountered are in accordance with the ISSC spectrum and therefore are acceptable for the study of ship responses.

The directional wave density spectrum is supposed to be represented by a onedimensional spectrum, and a directional function, i.e.

$$
S(\omega, \theta)=S_{\zeta}(\omega) D(\omega, \theta)
$$


where, $D(\omega, \theta)$ defines the proportion of the total energy propagating at an angle $\theta$ to the mean wave direction. With the directional spreading function defined so that its integral over all possible directions is unity constant:

$$
\int_{0}^{2 \pi} D(\omega, \theta) d \theta=1
$$

The directional function can be simply expressed as:

$$
D(\omega, \theta)=\left\{\begin{array}{c}
2 \cos ^{2} \theta / \pi, \quad-\frac{\pi}{2} \leq \theta \leq \frac{\pi}{2} \\
0, \quad \text { elsewhere }
\end{array}\right.
$$

Figure 7 shows the simulated directional wave spectrum corresponding to the measured sea state using the directional function in formula (11).

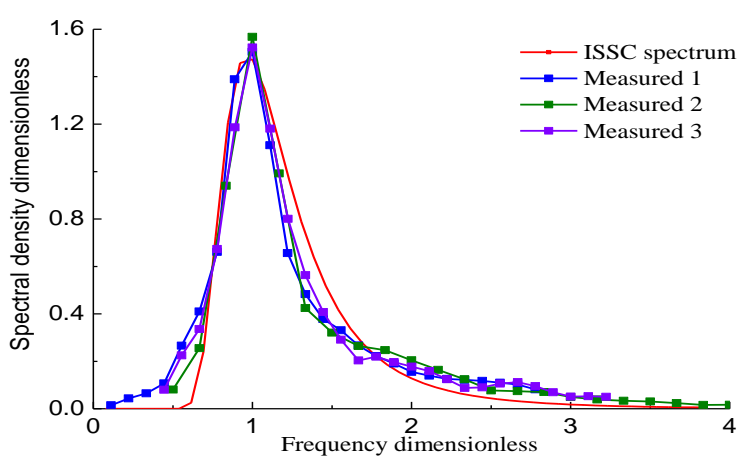

Figure 6 Comparison of the measured wave spectra with the ISSC spectrum

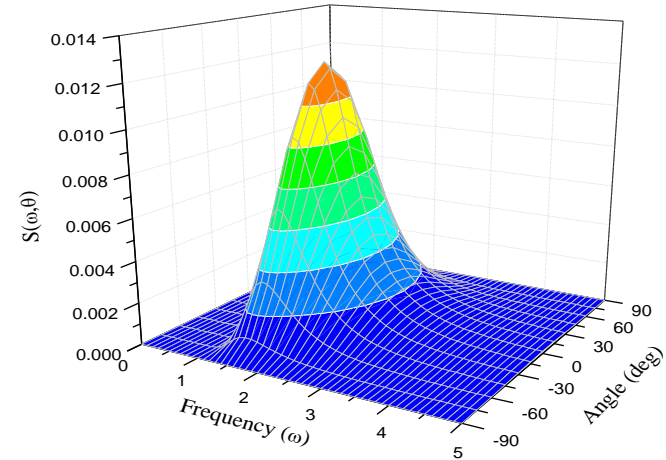

Figure 7 Simulated directional wave spectrum corresponding to measured sea state

According to the similitude law, the average significant wave height and the characteristic period are $14.3 \mathrm{~m}$ and $15.9 \mathrm{~s}$ corresponding to the ship prototype. It is almost the 9 th level sea state for the real ship. So this paper presents the most critical test cases under severe sea conditions.

\subsection{Motion and load responses in different sailing conditions}

The analysis of data was conducted as a post-voyage process. Based on the data obtained from measurements, some critical test cases with different heading angles and sailing speeds were selected for the investigation of the wave induced motions and loads. Spectral analyses of the measurements were performed to calculate the significant amplitude values. The results of representative testing conditions selected from the trial are shown in Table 2. In this study, pitch, roll, bow acceleration and VBM amidships are chosen for analysis, since they are representative of the wave-induced responses. The results of significant amplitude values were converted into the data of full-scale according to similitude law.

Table 2 Motion and load responses of representative testing conditions

\begin{tabular}{|c|c|c|c|c|c|}
\hline Speed $(\mathrm{knot})$ & Heading & Pitch $(\mathrm{deg})$ & Roll $(\mathrm{deg})$ & Acce $\left(\mathrm{m} / \mathrm{s}^{2}\right)$ & VBM $(\mathrm{MN} \cdot \mathrm{m})$ \\
\hline 0 & Head wave & 3.12 & 12.46 & 1.83 & 1915 \\
\hline 3 & Oblique wave & 2.82 & 12.83 & 1.72 & 1831 \\
\hline 5 & Head wave & 3.84 & 13.03 & 1.92 & 2151 \\
\hline 15 & Beam wave & 1.99 & 17.34 & 2.04 & 1636 \\
\hline 18 & Head wave & 4.07 & 8.38 & 3.51 & 2684 \\
\hline 24 & Head wave & 4.24 & 6.08 & 3.96 & 3008 \\
\hline
\end{tabular}


From the results in Table 2, it can be seen that responses of pitch, bow acceleration, and VBM amidships increase with the increasing forward speed in heading wave conditions. However, rolling motion depends little on the forward speed, and it is determined by heading angle and other factors. The rolling motion may even decrease with larger forward speed in some cases of heading waves. It is worth to mention that, when the model sailed in head seas, the roll motion was obvious with pronounced amplitude, which is quite different from the result obtained in the laboratory. In other words, sea waves spread along a dominant direction with components from different directions superimposed onto one another. The roll motion can be induced by component waves even when the ship runs against the dominant wave direction. However, the waves in the tank are usually unidirectional, thus the roll is nearly zero when performing head wave tests.

For the sake of clarity, typical time histories of representative signals are presented in Figure 8. The sailing speed in this illustrated example is selected as the design speed, i.e. 18 knots for the ship prototype and $1.852 \mathrm{~m} / \mathrm{s}$ for the model, and the heading angle is for head wave condition. Time histories of pitch and roll are illustrated in Figure 8(a) and (b), respectively. Vertical acceleration time history at the bow area is shown in Figure 8(c). VBM time history at amidships section is presented in Figure 8(d). Pressure signals of gauges 2 and 7 (see Figure 4) for flare slamming and bottom slamming are presented in Figure 8(e) and (f) respectively.

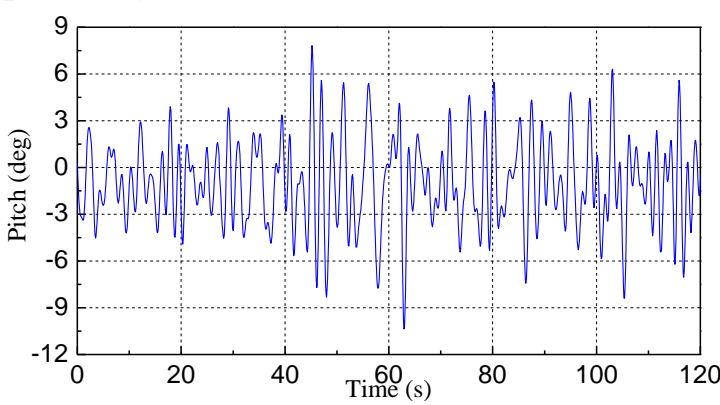

(a) Pitch

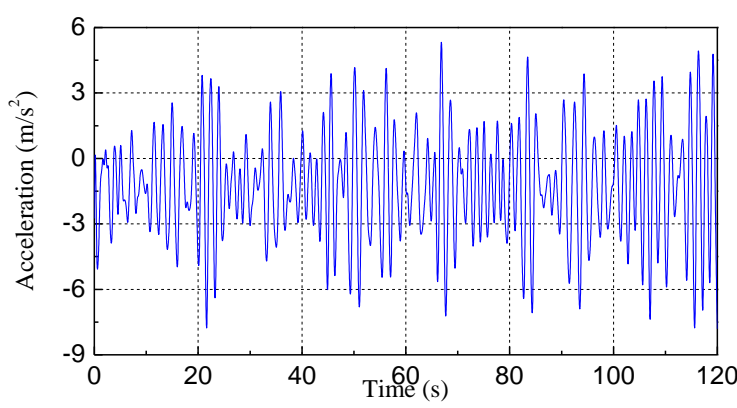

(c) Bow acceleration

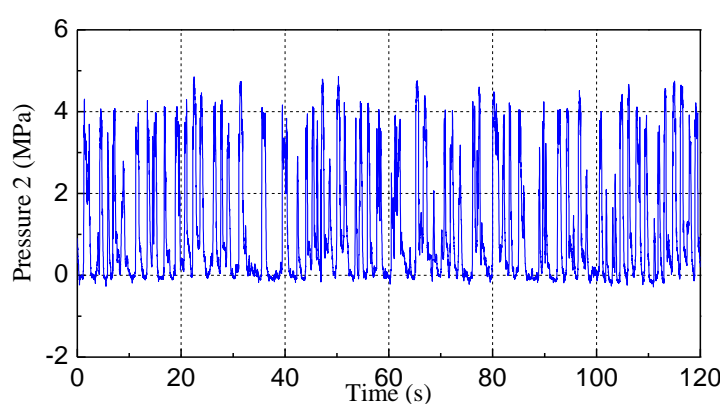

(e) Flare slamming

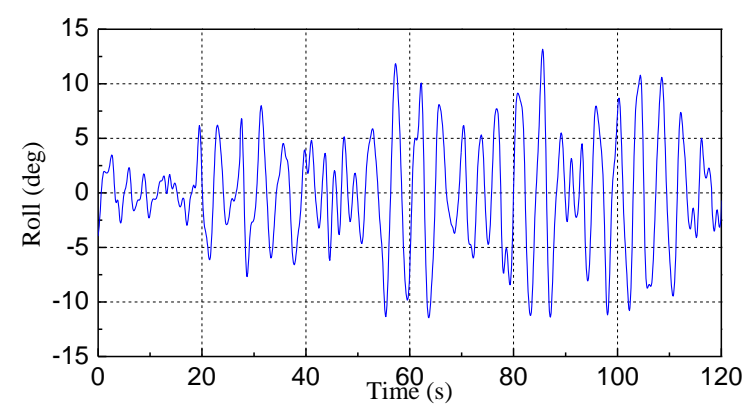

(b) Roll

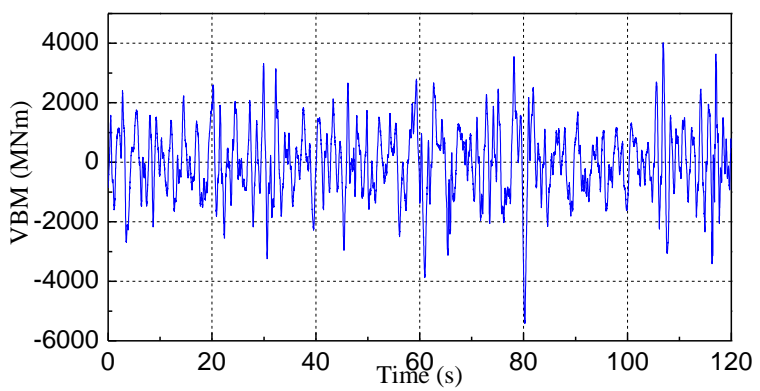

(d) VBM amidships

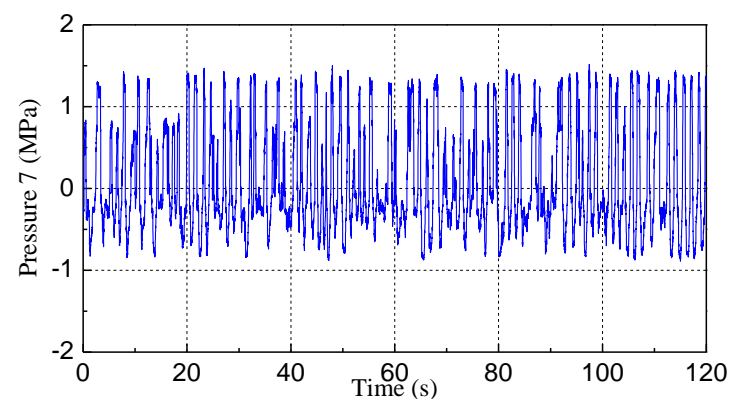

(f) Bottom slamming

Figure 8 Recorded time histories of representative signals 
Some typical scenes shot by camera (both the crew held camera and the one onboard the model) are shown in Figure 9.

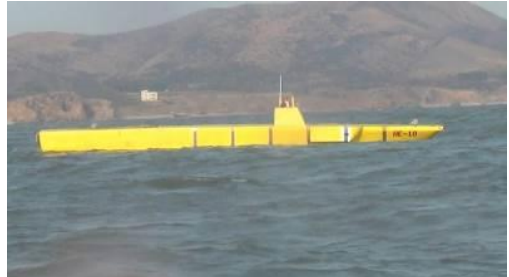

(a) Head waves

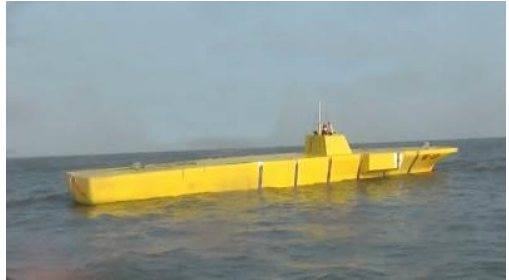

(d) Port quarter waves

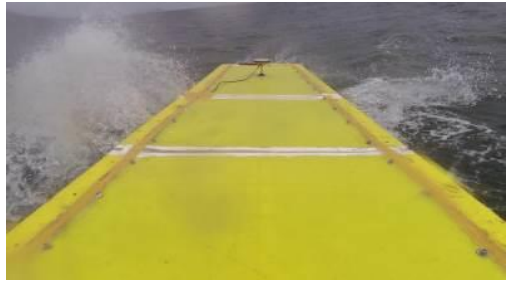

(g) Green water on the deck

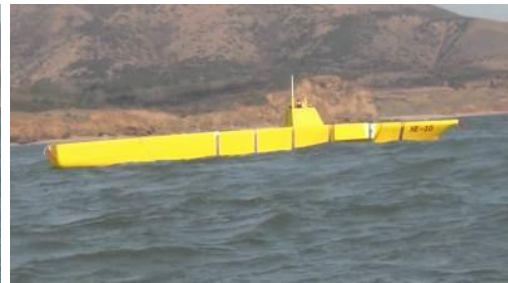

(b) Following waves

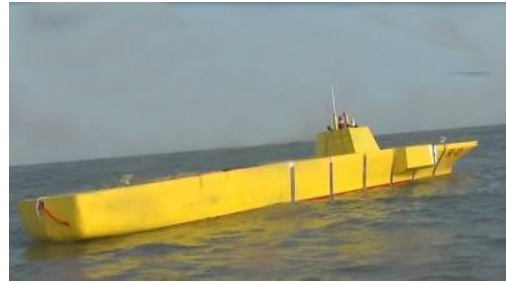

(e) Starboard bow waves

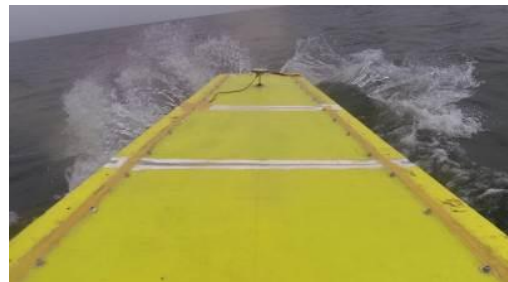

(h) Bow slamming

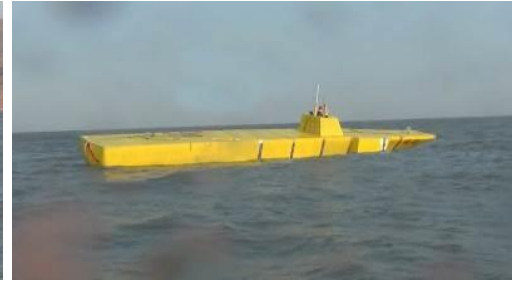

(c) Port beam waves

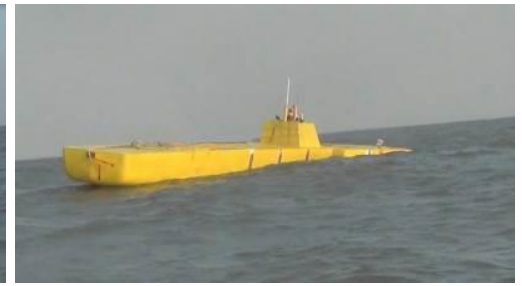

(f) Stern emergence

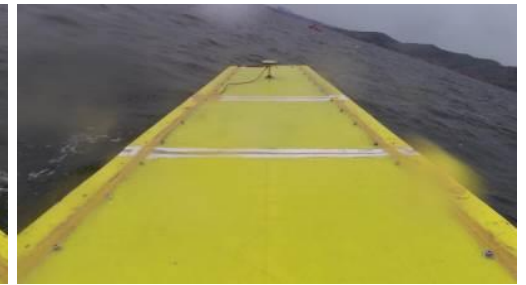

(i) Large-amplitude rolling

Figure 9 Pictures recorded by camera during the voyage

\section{Short-term extreme distribution with statistical model}

For the further analysis of the measured data, short-term extreme values distribution of the responses under the corresponding sea condition is made. A ship which is often operated within a fixed route and task can control neither the environmental conditions nor the sailing conditions [17]. In this case, it is of great importance to estimate the ship's responses under the often encountered sea states. Statistical values such as maximum, minimum, and peakpeak (P-P) value of pitch, roll, bow acceleration and VBM amidships were extracted in every 20 -second range from the measured time histories. The 20 -second range method is widely used in the data analysis for the real ship sea trial to enhance the computer processing speed. It is considered that adjacent 20 -second statistics are statistically independent of each other. Figure 10 shows maximum, minimum and peak-peak values of pitch, roll, bow acceleration and VBM amidships during every 20 seconds for the 130-minute voyage.

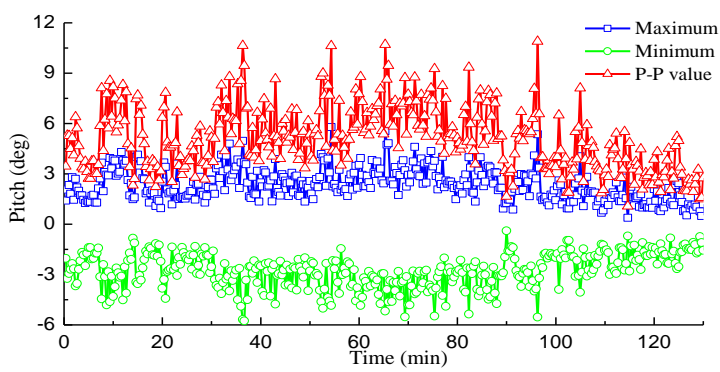

(a) Pitch

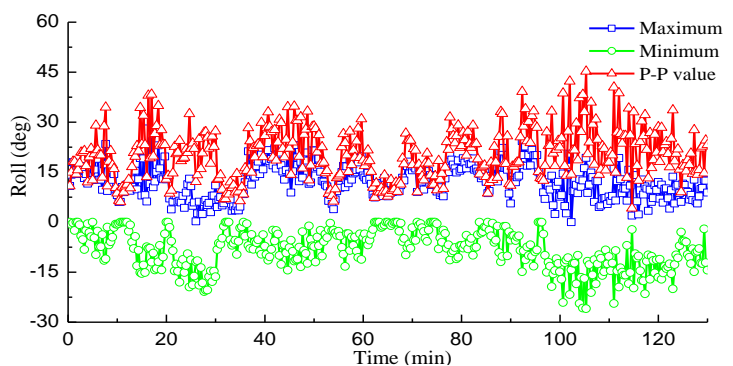

(b) Roll 


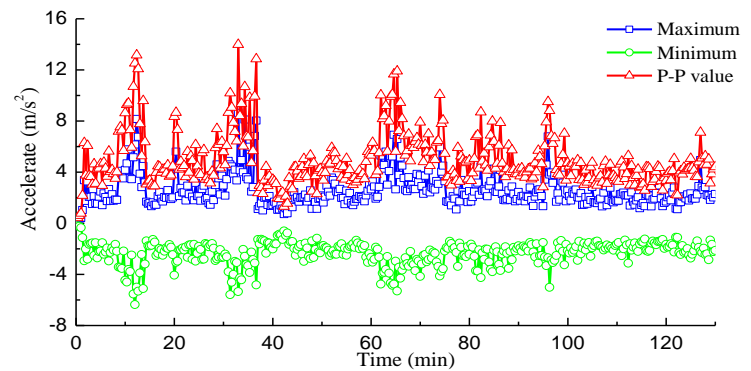

(c) Bow acceleration

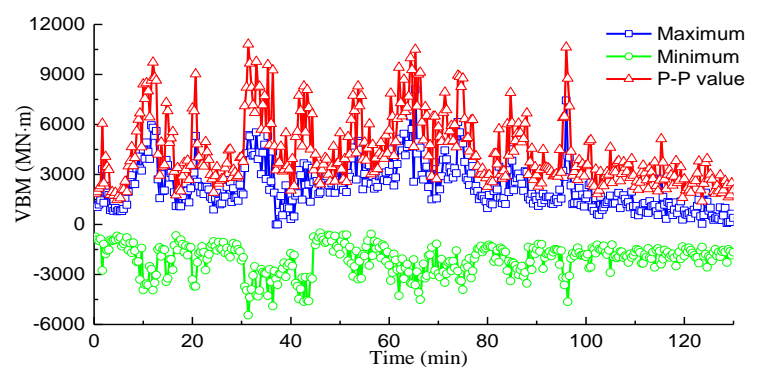

(d) VBM amidships

Figure 10 Time histories of 20-second statistics

As can be seen from the above figure, the tendency of vertical responses, i.e. pitch, bow acceleration and VBM amidships, are consistent with each other. Some notable large responses took place at the 12th, 31st, 65th, and 96th minutes as seen from the outliers in the figure. By checking the video playback, it was found that the model had encountered severe head waves at these times. From the experimental results, the roll response looks independent of the vertical responses and shows a different trend. For example, in the period from 100 to 130 minutes, the model travelled with a low forward speed or even stopped for some tasks at some time, so the vertical responses seem to be small, however, the rolling motion seems to be pronounced.

The commonly used statistical model, the Weibull distribution, is applied to the calculation of short-term extreme values. Graphical representations of the statistical peakpeak value with a histogram of the measured 130-minute recorded data as well as the Weibull fitted result are shown in Figure 11. Each figure presents counts of wave induced component calculated from Figure 10 with respect to the peak-peak values of pitch, roll, bow acceleration and VBM amidships. There are 390 samples in total for each statistic. As seen from the histograms in Figure 11, the statistics of motions shows a good agreement with the Weibull distribution. However, the statistics of acceleration and load show differences between the measurement and the Weibull statistical model because of the nonlinear response caused by severe waves.

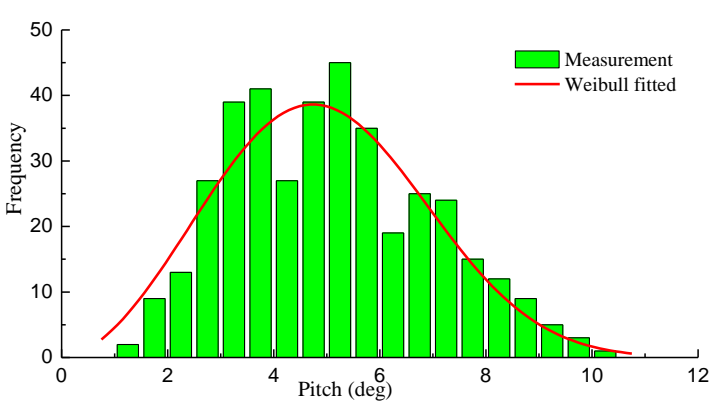

(a) Pitch

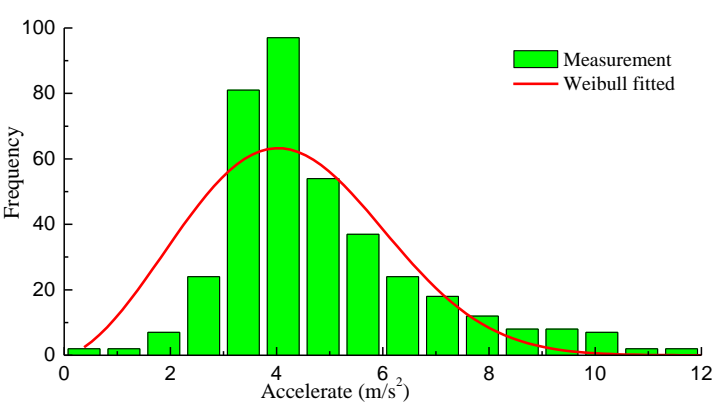

(c) Bow acceleration

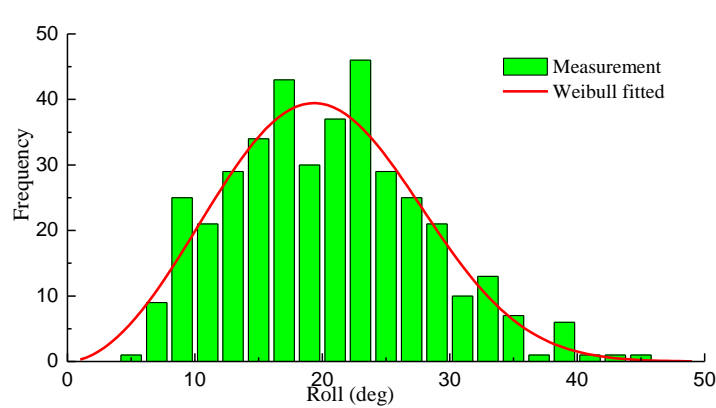

(b) Roll

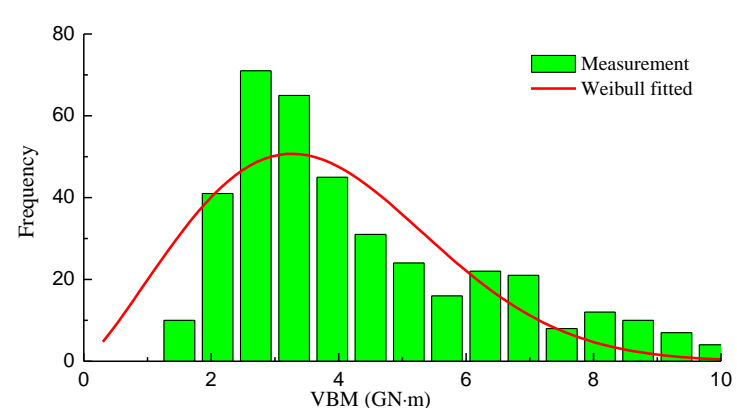

(d) VBM amidships

Figure 11 Histogram of peak-peak value distributions 
The extreme value is defined as the largest value of a random variable expected to occur once in $n$ independent samples. Suppose $X=\left(x_{1}, x_{2}, \ldots, x_{n}\right)$ are random samples of size $n$, and by arranging these random samples in order from the smallest to the largest we get $Y=\left(y_{1}, y_{2}\right.$, $\left.\ldots, y_{n}\right)$, i.e. $y_{1}$ is the smallest one and $y_{n}$ is the largest one in $n$ samples [18-19]. The largest one in $n$ samples, $y_{n}$, is called the extreme value.

Suppose the random variable $X$ is of the Weibull distribution, then the probability density function and cumulative distribution function of variable $x$, which represents the statistics amplitude or peak-peak value, can be written as follows:

$$
\begin{aligned}
& f_{X}(x)=\frac{l}{k}\left(\frac{x}{k}\right)^{l-1} e^{-\left(\frac{x}{k}\right)^{l}} \\
& F_{X}(x)=1-e^{-\left(\frac{x}{k}\right)^{l}}
\end{aligned}
$$

where, $l$ and $k$ are parameters of the Weibull distribution.

The cumulative distribution function and the probability density function of $Y_{n}$, the extreme value of random variable $X$, can be written as follows:

$$
\begin{aligned}
& G_{Y_{n}}(y)=\left[F_{X}(y)\right]^{n}=\left[1-e^{-\left(\frac{y}{k}\right)^{l}}\right]^{n} \\
& g_{Y_{n}}(y)=n\left[F_{X}(y)\right]^{n-1} f_{X}(y)=\frac{n l}{k}\left(\frac{y}{k}\right)^{l-1} e^{-\left(\frac{y}{k}\right)^{l}}\left[1-e^{-\left(\frac{y}{k}\right)^{l}}\right]^{n-1}
\end{aligned}
$$

The probability that the response exceeds a specified value $\bar{Y}_{n}$, can be obtained by formula (14), is that:

$$
P\left(Y>\overline{Y_{n}}\right)=1-\left[1-e^{-\left(\frac{\overline{Y_{n}}}{k}\right)^{l}}\right]^{n}
$$

If the probability in formula (16) is $\beta$, then the extreme value is given as:

$$
\widehat{Y}_{n}(\beta) \approx k\left\{\ln \left[1-(1-\beta)^{1 / n}\right]^{-1}\right\}^{1 / l}
$$

It is known that when $\beta=0.632$, the obtained extreme value is the most probable one, i.e. the value corresponding to the peak of probability density curve of formula (15). Usually $\beta=0.01$ is selected in engineering applications. The comparative analysis of experimental results and predictions by the Weibull fitted functions is summarized in Table 3 . Since the estimation of extreme values is based on the peak-peak values, the extreme values obtained are also in the peak-peak form.

Table 3 Comparison of extreme peak-peak values during the voyage

\begin{tabular}{|c|c|c|c|c|c|}
\hline \multirow{2}{*}{ Item } & \multicolumn{2}{|c|}{ Experimental data } & \multicolumn{3}{c|}{ Prediction } \\
\cline { 2 - 6 } & Average & Extreme & Average & $Y_{n}(0.632)$ & $Y_{n}(0.01)$ \\
\hline Pitch $(\mathrm{deg})$ & 5.09 & 10.89 & 5.00 & 10.57 & 12.98 \\
\hline Roll $(\mathrm{deg})$ & 20.33 & 45.21 & 20.00 & 41.73 & 50.88 \\
\hline Acce $\left(\mathrm{m} / \mathrm{s}^{2}\right)$ & 4.93 & 13.99 & 4.33 & 9.62 & 11.99 \\
\hline VBM $(\mathrm{MN} \cdot \mathrm{m})$ & 4370 & 10800 & 3790 & 9660 & 12520 \\
\hline
\end{tabular}


As seen from Table 3, the measured and predicted extreme values of motion responses, i.e. pitch and roll, show good agreement with each other. The errors of the predicted extreme values of pitch and roll responses are 3\% and $8 \%$ respectively when compared with the experimental data. However, the extreme values of acceleration and VBM responses predicted by the Weibull function are $31 \%$ and $11 \%$ lower than the experimental data. The reason is that the simulation time of the trial is short, just slightly above two hours. Moreover, the speed and the direction angle during the trial are not constant. The severe slamming loads can also make the distribution of total load depart from the Weibull distribution, which can be explained by the fact that the instantaneous sagging loads caused by bow slamming may be several times larger than those caused by the low frequency wave loads. However, the predictions by the in the peak-peak form Weibull function assume that the loads are linear and stable, which is not suitable for slamming cases.

\section{Numerical simulations}

An in-house code, the Linear Elastic Wave Loads Calculation System (WALCS-LE), was used to predict the wave induced motions and load responses. The code is based on the linear frequency-domain hydroelasticity theory. Other details regarding the code can be found in [20-21]. While the large-scale measurements provide valuable data in simulation of real vessel operations, the actual natural conditions cannot be controlled, such as the wave environments or the voyage period. Thus, the numerical method is also desirable to investigate the ship's long-term prediction of extreme values.

The procedure adopted for assessing the wave-induced motions and load responses is based on the transfer functions predicted by the linear theory. Since the time domain elevations such as waves and other response signals, could be regarded as a stationary Gaussian stochastic process in the linear theory, this satisfies the requirements of engineering accuracy. The wave induced motions and load responses are the output of a system that is linear to the input waves. The relationship between the incident waves and the output response in three-dimensional irregular waves can be expressed as follows:

$$
S\left(\omega, H_{1 / 3}, T, V, \beta+\theta\right)=H^{2}(\omega, V, \beta+\theta) S_{\zeta}\left(\omega, H_{1 / 3}, T, \theta\right)
$$

where, $\omega$ is natural frequency, $H_{1 / 3}$ is significant wave height, $T$ is wave characteristic period, $V$ is sailing speed, $\beta$ is heading angle, $\theta$ is angle between component and main wave direction, $S\left(\omega, H_{1 / 3}, T, V, \beta+\theta\right)$ is response function of motions or loads, $H(\omega, V, \beta+\theta)$ is transfer function of motion or load response, $S_{\zeta}\left(\omega, H_{1 / 3}, T, \theta\right)$ is wave spectral density function.

The variance of formula (18), i.e. the volume below the curved surface of response function, can be derived by:

$$
m\left(H_{1 / 3}, T, V, \beta\right)=\int_{-\pi / 2}^{\pi / 2} \int_{0}^{\infty} S\left(\omega, H_{1 / 3}, T, V, \beta+\theta\right) d \omega d \theta
$$

Characteristic values such as significant amplitude value of short-term responses can be obtained as follows:

$$
x_{1 / 3}=2 \sqrt{m\left(H_{1 / 3}, T, V, \beta\right)}
$$

Generally, the long-term prediction can be carried out by short-term responses with respect to various sea states, specified by the significant wave height $H_{1 / 3}$, and the characteristic period $T_{P}$, and then extended to the long-term prediction by considering the wave scatter diagram. 
The probability of exceeding a given level $x$ of response amplitude value, in a specified environmental condition, can be obtained by the Rayleigh distribution:

$$
P_{i j k}(x)=\exp \left\{-x^{2} / E\left[\left(H_{1 / 3}, T\right)_{i}, \beta_{j}, V_{k}\right]\right\}
$$

where, $E\left[\left(H_{1 / 3}, T\right)_{i}, \beta_{j}, V_{k}\right]$ denotes twice of the variance, and can be obtained by the formula:

$$
E\left[\left(H_{1 / 3}, T\right)_{i}, \beta_{j}, V_{k}\right]=2 m\left(H_{1 / 3}, T, V, \beta\right)
$$

The long-term distribution is obtained by summation of short-term probabilities of exceedance in all possible combinations of wave characteristic periods, significant wave heights, heading angles and speeds. In the long-term prediction of ship motions and loads responses at different navigational conditions, the probability of exceedance, i.e. the probability that $X$ will be larger than $x$, is given as:

$$
P(X \geq x)=\sum_{i} \sum_{j} \sum_{k} p_{i}\left(H_{1 / 3}, T\right) p_{j}(\beta) p_{k}(V) \exp \left\{-x^{2} / E\left[\left(H_{1 / 3}, T\right)_{i}, \beta_{j}, V_{k}\right]\right\}
$$

where, $P_{i(j, k)}$ denotes the occurrence probability of the corresponding condition.

A completely independent calculation using formula (18) will be carried out for each sailing condition. In order to improve the computational efficiency, the conditions suffered during the ship's lifetime were simplified by dividing them into several discrete points. It is said in [19] that the discretization has little influence on the result and can be ignored. In this study, four sailing speeds were considered, i.e. 0 knots, 5 knots, 18 knots, and 24 knots, and the probabilities for each speed are equal. Heading angles ranged from 0 to 360 degrees and were divided into 24 representative values with the same interval of 15 degrees and the probabilities of each heading angle were assumed to be equal. The North Atlantic open sea area was adopted in this study and the wave data are shown in Table 4. The ISSC double parameters wave spectrum is selected for the simulation of sea waves in all cases. It is assumed that the incident waves are short-crested and with the dimensional function of

\begin{tabular}{|c|c|c|c|c|c|c|c|c|c|c|c|c|c|c|c|c|c|c|c|}
\hline $\mathrm{Hs} / \mathrm{T}$ & 1.5 & 2.5 & 3.5 & 4.5 & 5.5 & 6.5 & 7.5 & 8.5 & 9.5 & 10.5 & 11.5 & 12.5 & 13.5 & 14.5 & 15.5 & 16.5 & 17.5 & 18.5 & Sum \\
\hline 0.5 & & & 1.3 & 133 & 865 & 1186 & 634 & 186 & 36.9 & 5.6 & 0.7 & 0.1 & & & & & & & 3050 \\
\hline 1.5 & & & & 29.3 & 986 & 4976 & 7738 & 5569 & 2375 & 703 & 160 & 30.5 & 5.1 & 0.8 & 0.1 & & & & 22575 \\
\hline 2.5 & & & & 2.2 & 197 & 2158 & 6230 & 7449 & 4860 & 2066 & 644 & 160 & 33.7 & 6.3 & 1.1 & 0.2 & & & 23810 \\
\hline 3.5 & & & & 0.2 & 34.9 & 695 & 3226 & 5675 & 5099 & 2838 & 1114 & 377 & 84.3 & 18.2 & 3.5 & 0.6 & 0.1 & & 19128 \\
\hline 4.5 & & & & & 6 & 196 & 1354 & 3288 & 3857 & 2685 & 1275 & 455 & 130 & 31.9 & 6.9 & 1.3 & 0.2 & & 13289 \\
\hline 5.5 & & & & & 1 & 51 & 498 & 1602 & 2372 & 2008 & 1126 & 463 & 150 & 41 & 9.7 & 2.1 & 0.4 & 0.1 & 8328 \\
\hline 6.5 & & & & & 0.2 & 12.6 & 167 & 690 & 1257 & 1268 & 825 & 386 & 140 & 42.2 & 10.9 & 2.5 & 0.5 & 0.1 & 4806 \\
\hline 7.5 & & & & & & 3 & 52.1 & 270 & 594 & 703 & 524 & 276 & 111 & 36.7 & 10.2 & 2.5 & 0.6 & 0.1 & 2586 \\
\hline 8.5 & & \multicolumn{3}{|c|}{ Percentage } & & 0.7 & 15.4 & 97.9 & 255 & 350 & 296 & 174 & 77.6 & 27.7 & 8.4 & 2.2 & 0.5 & 0.1 & 1309 \\
\hline 9.5 & & & \multicolumn{2}{|c|}{$0-100$} & & 0.2 & 4.3 & 33.2 & 101 & 159 & 152 & 99.2 & 48.3 & 18.7 & 6.1 & 1.7 & 0.4 & 0.1 & 626 \\
\hline 10.5 & & & \multicolumn{2}{|c|}{$100-500$} & & & 1.2 & 10.7 & 37.9 & 67.5 & 71.7 & 51.5 & 27.3 & 11.4 & 4 & 1.2 & 0.3 & 0.1 & 285 \\
\hline 11.5 & & & \multicolumn{2}{|c|}{$\begin{array}{l}500-1000 \\
\end{array}$} & & & 0.3 & 3.3 & 13.3 & 26.6 & 31.4 & 24.7 & 14.2 & 6.4 & 2.4 & 0.7 & 0.2 & 0.1 & 124 \\
\hline 12.5 & & & \multicolumn{2}{|c|}{$1000-2000$} & & & 0.1 & 1 & 4.4 & 9.9 & 12.8 & 11 & 6.8 & 3.3 & 1.3 & 0.4 & 0.1 & & 51 \\
\hline 13.5 & & & \multicolumn{2}{|c|}{$2000-3000$} & & & & 0.3 & 1.4 & 3.5 & 5 & 4.6 & 3.1 & 1.6 & 0.7 & 0.2 & 0.1 & & 21 \\
\hline 14.5 & & & \multicolumn{2}{|c|}{$3000-5000$} & & & & 0.1 & 0.4 & 1.2 & 1.8 & 1.8 & 1.3 & 0.7 & 0.3 & 0.1 & & & 8 \\
\hline 15.5 & & & \multicolumn{2}{|c|}{$5000-7000$} & & & & & 0.1 & 0.4 & 0.6 & 0.7 & 0.5 & 0.3 & 0.1 & 0.1 & & & 3 \\
\hline 16.5 & & & \multicolumn{2}{|c|}{ 7000- } & & & & & & 0.1 & 0.2 & 0.2 & 0.2 & 0.1 & 0.1 & & & & 1 \\
\hline Sum & 0 & 0 & 1 & 165 & 2091 & 9280 & 1992 & 2487 & 2087 & 1289 & 6245 & 2479 & 837 & 247 & 66 & 16 & 3 & 1 & 100000 \\
\hline
\end{tabular}
formula (11).

Table 4 Scatter diagram for the North Atlantic sea states

In order to obtain the transfer functions $H(\omega, V, \beta+\theta)$, the WALCS-LE was used to calculate the response of the ship prototype under different conditions. The generated hydrodynamic mesh of the ship prototype is presented in Figure 12. This hydrodynamic mesh was used for the hydrodynamic analyses based on the linear frequency-domain hydroelastic method. The mesh has 1242 panels with a ratio of length to width of 2.5. In this simulation, the fluid domain was set with an infinite depth. Critical damping method was adopted for roll damping correction. The structural idealization of the backbone was by a beam model 
accounting for the stiffness longitudinal distribution. The calculation incident wave frequencies were set from 0.05 to $2 \mathrm{rad} / \mathrm{s}$ with a step of $0.05 \mathrm{rad} / \mathrm{s}$. The results of response amplitude operators (RAOs) obtained by the code are summarized in Figure 13.

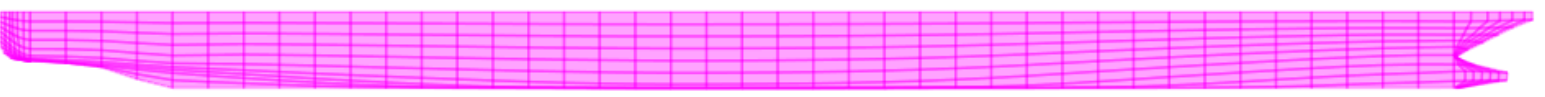

Figure 12 Hydrodynamic mesh of the geometry model
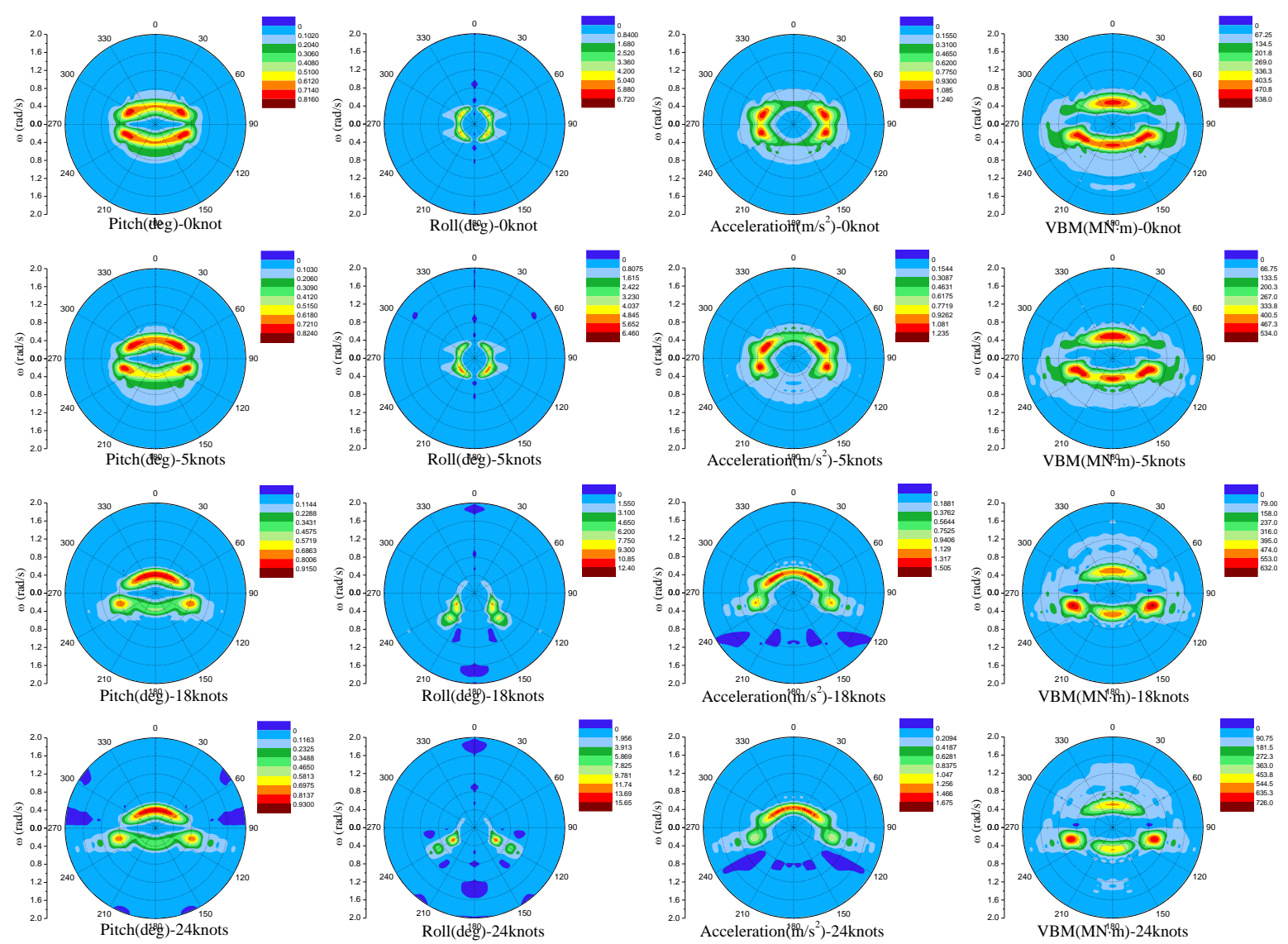

Figure 13 Transfer functions under different conditions

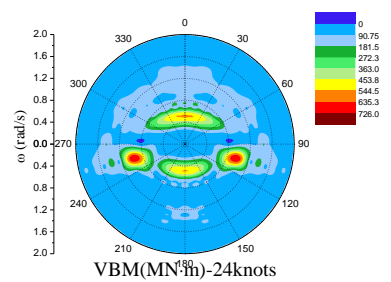

With the known wave energy spectra and the calculated frequency characteristics of the responses of the ship, the response spectra and the statistics of these responses can be made.

\subsection{Results of short-term prediction}

The numerical simulation results of the short-term prediction in the corresponding sea conditions $\left(H_{1 / 3}=14.5 \mathrm{~m}, T_{z}=15.5 \mathrm{~s}\right)$ are summarized in Figure 14. The results are given corresponding to significant amplitude value.

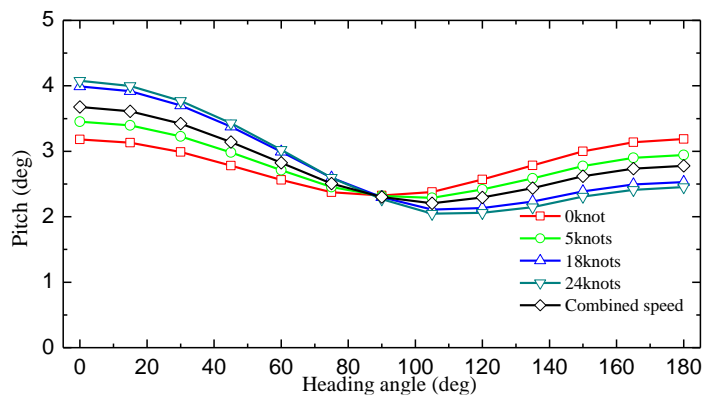

(a) Pitch

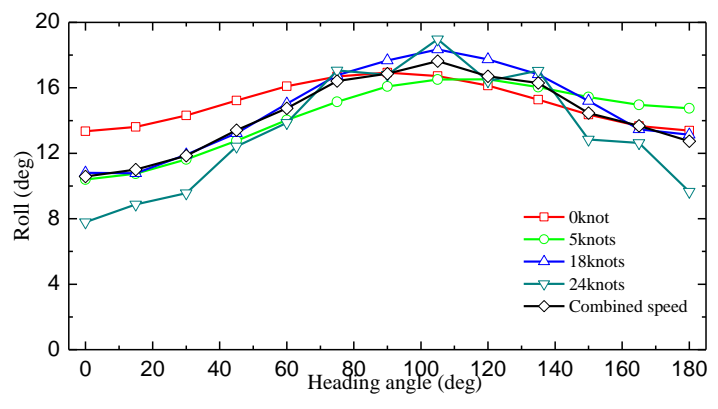

(b) Roll 


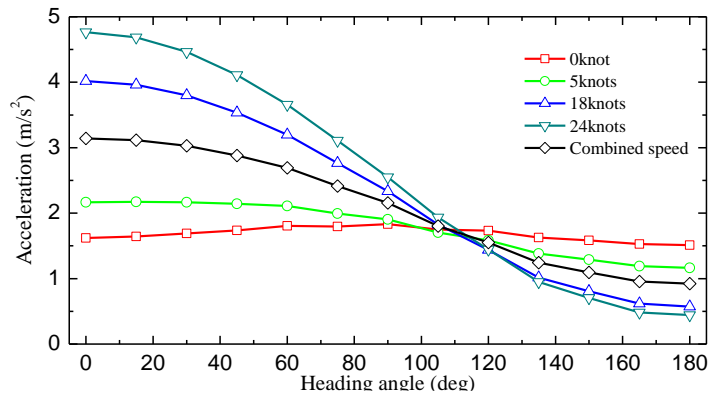

(c) Bow acceleration

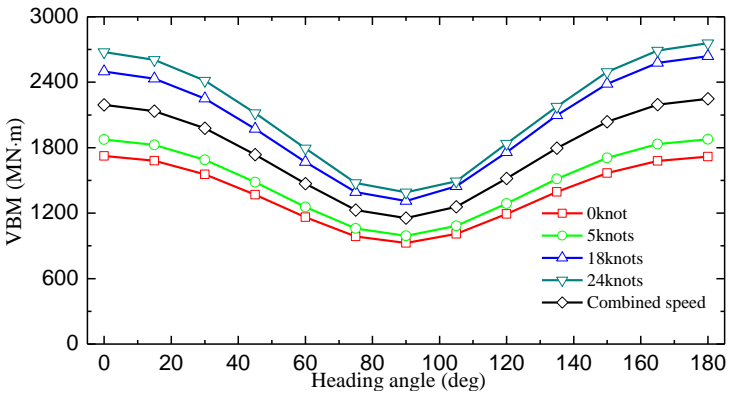

(d) VBM amidships

Figure 14 Short-term prediction at corresponding sea state

In order to compare the experimental and the numerical results of short-term predictions, the significant amplitude values of responses for head wave conditions corresponding to sailing conditions in Table 2 are summarized in Table 5.

Table 5 Comparison of significant amplitude values in head wave conditions

\begin{tabular}{|c|c|c|c|c|c|c|c|c|c|c|c|c|}
\hline \multirow{2}{*}{$\begin{array}{c}\text { Speed } \\
\text { (knot) }\end{array}$} & \multicolumn{3}{|c|}{ Pitch (deg) } & \multicolumn{3}{c|}{ Roll (deg) } & \multicolumn{3}{c|}{ Acce $\left(\mathrm{m} / \mathrm{s}^{2}\right)$} & \multicolumn{3}{c|}{ VBM (MN·m) } \\
\hline 0 & 3.12 & 3.18 & $2 \%$ & 12.46 & 13.35 & $7 \%$ & 1.83 & 1.62 & $11 \%$ & 1915 & 1724 & $10 \%$ \\
\hline 5 & 3.84 & 3.45 & $10 \%$ & 13.03 & 10.39 & $20 \%$ & 1.92 & 2.16 & $13 \%$ & 2151 & 1874 & $13 \%$ \\
\hline 18 & 4.07 & 3.99 & $2 \%$ & 8.38 & 10.81 & $29 \%$ & 3.51 & 4.02 & $15 \%$ & 2684 & 2497 & $7 \%$ \\
\hline 24 & 4.24 & 4.08 & $4 \%$ & 6.08 & 7.79 & $28 \%$ & 3.96 & 4.77 & $20 \%$ & 3008 & 2676 & $11 \%$ \\
\hline
\end{tabular}

The statistical result of the heading angles indicated that the heading directions were arbitrary and ergodic during the voyage trial. The short-term prediction of the ship's responses under combined average sailing conditions was made using the data in Figure 14 by assuming the probabilities of each heading angle and each speed to be equal. The comparative results by the experimental and numerical methods are shown in Table 6. For the sake of completeness, a histogram representation of the response values is shown in Figure 15. In the figure, the experimental response data are assumed to be unity, and calculated response data are the ratio of the calculation value to the experiment value.

Table 6 Comparison of significant amplitude values in comprehensive conditions

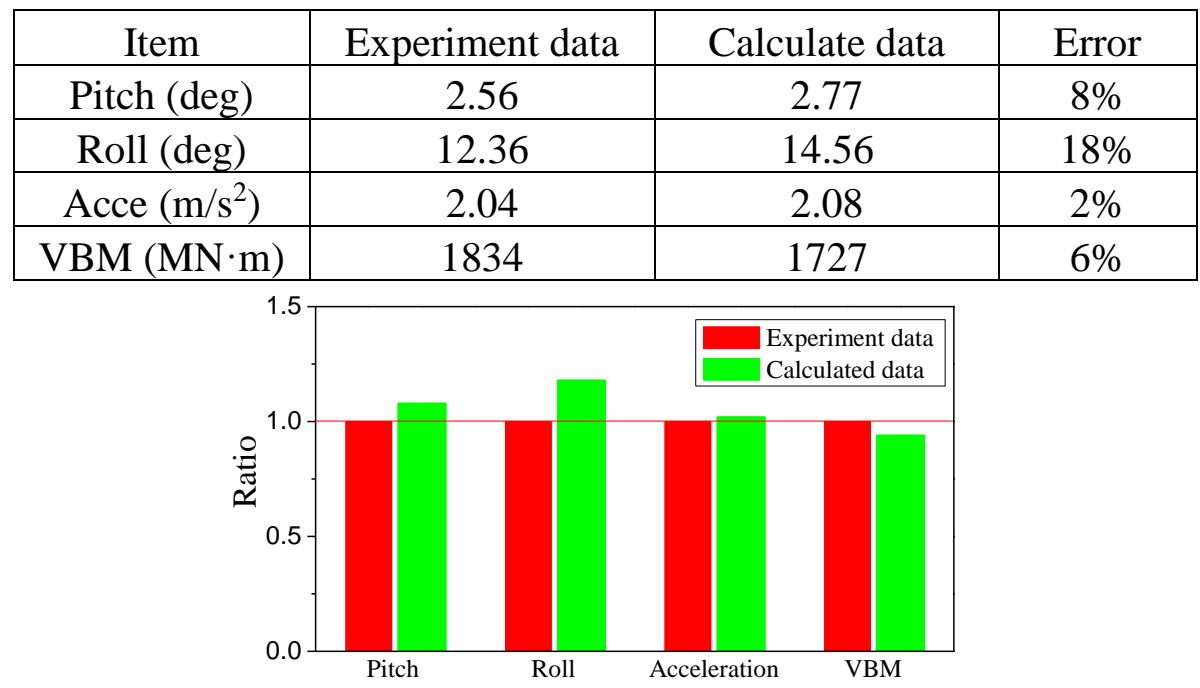

Figure 15 Comparison of response in comprehensive conditions

As shown in Figure 15, the calculated results of the short-term prediction indicate good agreement with the experiment results for vertical responses, i.e. pitch, acceleration, and VBM. However, the numerical method overestimates the rolling motion of the ship by $18 \%$. 


\subsection{Results of long-term prediction}

Figure 16 displays the long-term prediction results of probability of exceedance by numerical method for different sailing speeds. The results denote the response significant amplitude values.

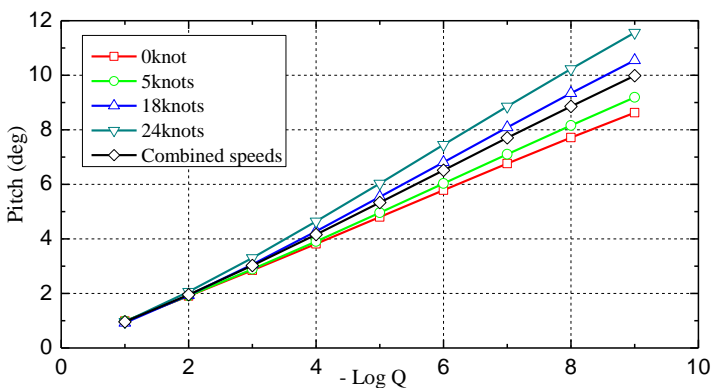

(a) Pitch

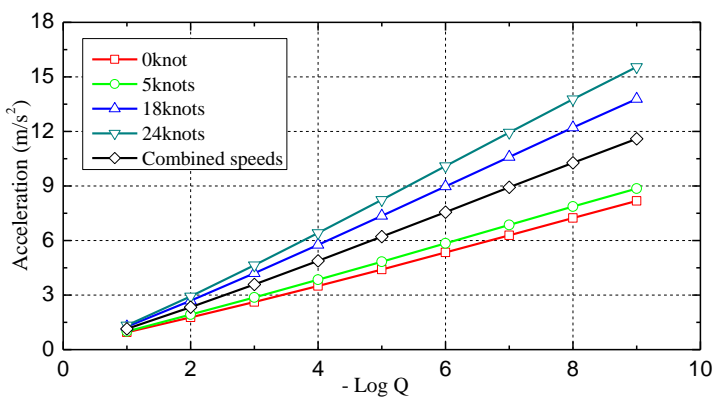

(c) Bow acceleration

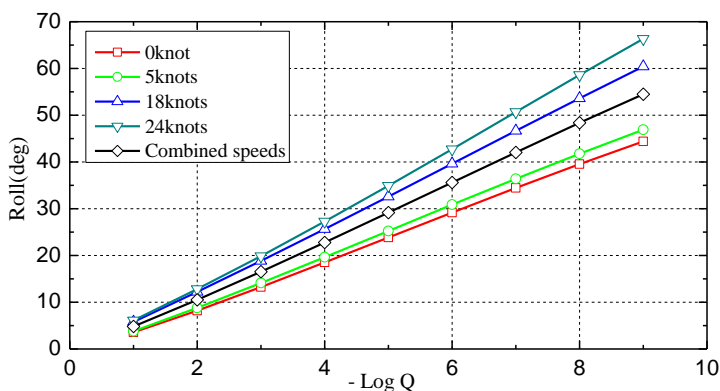

(b) Roll

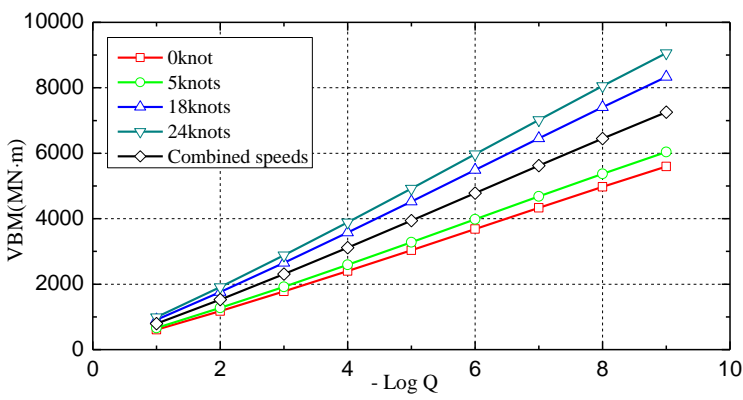

(d) VBM amidships

Figure 16 Results of long-term predictions

Probability of exceedance $Q$ is the reciprocal of the number $n$, i.e. the number of waves encountered by a ship during the return period. Assuming that the average wave period is 6.3 $\mathrm{s}$, then the probabilities of exceedance are $10^{-7}$ and $10^{-8}$ respectively corresponding to the 2year and 20-year return periods. The predicted extreme values of the 2-year and 20-year return periods are summarized in Table 7.

Table 7 Results of long-term predictions

\begin{tabular}{|c|c|c|c|c|c|c|c|c|}
\hline \multirow{2}{*}{$\begin{array}{c}\text { Speed } \\
(\text { knot })\end{array}$} & \multicolumn{2}{|c|}{ Pitch $(\mathrm{deg})$} & \multicolumn{2}{c|}{ Roll $(\mathrm{deg})$} & \multicolumn{2}{c|}{ Acce $\left(\mathrm{m} / \mathrm{s}^{2}\right)$} & \multicolumn{2}{c|}{ VBM $(\mathrm{MN} \cdot \mathrm{m})$} \\
\cline { 2 - 10 } & $2-\mathrm{Y}$ & $20-\mathrm{Y}$ & $2-\mathrm{Y}$ & $20-\mathrm{Y}$ & $2-\mathrm{Y}$ & $20-\mathrm{Y}$ & $2-\mathrm{Y}$ & $20-\mathrm{Y}$ \\
\hline 0 & 6.76 & 7.71 & 34.44 & 39.54 & 6.29 & 7.24 & 4333 & 4971 \\
\hline 5 & 7.11 & 8.16 & 36.39 & 41.74 & 6.86 & 7.87 & 4671 & 5369 \\
\hline 18 & 8.09 & 9.34 & 46.66 & 53.60 & 10.60 & 12.22 & 6456 & 7407 \\
\hline 24 & 8.86 & 10.23 & 50.68 & 58.62 & 11.95 & 13.84 & 7019 & 8053 \\
\hline Combined & 7.70 & 8.86 & 42.04 & 48.37 & 8.92 & 10.27 & 5622 & 6450 \\
\hline
\end{tabular}

As seen from Table 7, the 20-year long-term predictions are about 13\% larger than the 2 -year predictions for all of the four responses in combined average conditions. The pitch, roll, acceleration, and VBM extreme amplitude values are $5.45^{\circ}, 24.11^{\circ}, 7 \mathrm{~m} / \mathrm{s}^{2}$ and $5400 \mathrm{MN} \cdot \mathrm{m}$, respectively during the 2-hour voyage (see Table 3), and they are $29 \%, 43 \%, 22 \%$ and $4 \%$, respectively lower than the long-term predictions of the 2-year return period in combined average conditions. 


\section{Conclusions}

This paper presents a novel measurement technique for ship motions and load responses in real sea waves. The main advantage of the proposed method is that the tests are for shortcrested and wind-generated wave measurements. The ship models are complete with their superstructures and the winds, waves as well as currents interaction effects are considered. The tests are carried out at any arbitrary heading angles with less scale effects. This testing condition is much more realistic than the traditional tank condition. Moreover, the large-scale model measurements also have the advantages over full-scale sea trials. The cost for implementing large-scale tests is much lower than for full-scale sea trials and more extreme sea states can be easily encountered by the large-scale models.

A recent sea trial was performed at Huludao harbor in October 2014. The 2-hour voyage proved that the assembled testing platform was reliable enough. Based on this study, the following conclusions can be made:

(1) It has been proved by the experiments that the remote control systems and telemetry systems, which lay the solid foundation for the voyage trials, are stable enough to meet the experimental demands.

(2) It has been confirmed that the coastal waves in sheltered waters measured during the tests are similar to the deep-ocean waves by comparing the sampled wave spectra with the ISSC double parameters spectrum. Therefore, it is reasonable to carry out the measurements in coastal waves and extrapolate the results to the real ship responses in deep seas in this study.

(3) From the analysis of motions and load responses under different sailing conditions during the 2-hour simulation exercises, it can be clearly found that the six-degrees of freedom motions of the model in short-crested wind generated waves are coupled even when the model runs in head seas.

(4) The results of extreme values predicted by the Weibull fitted function show good agreements with the experimental data in motion responses, i.e. pitch and roll. However, extreme values of acceleration and load responses in severe seas predicted by the Weibull fitted function are underestimated. This can be attributed to the nonlinear effects caused by the severe waves during the trial.

(5) By comparing the results of short-term predictions in combined average sailing conditions by experimental and numerical methods, it is found that the results of vertical responses, i.e. pitch, roll and VBM, show good agreements, each with an error of less than $8 \%$. The rolling motion response value by numerical method is $18 \%$ larger than the experimental value.

\section{ACKNOWLEDGEMENTS}

The authors thank the reviewers for their valuable remarks and comments. Special thanks are due to technical engineer Zhao Xiaodong and all the trial participants for their kind help during the preparation and implementation of the tests. This work was supported by the National Natural Science Foundations of China (NO. 51079034 and NO. 51209054). The authors express their gratitude to these foundations. 
Predictions of wave induced ship motions and loads by large-scale model measurement at sea and numerical analysis

\section{REFERENCES}

[1] G.S. Baarholm, T. Moan: Estimation of nonlinear long-term extremes of hull girder loads in ships. Marine Structures, Vol.13, pp495-516, (2000). http://dx.doi.org/10.1016/S0951-8339(00)00060-5.

[2] M.K. Wu, O.A. Hermundstad: Time-domain simulation of wave-induced nonlinear motions and loads and its applications in ship design. Marine Structures, Vol.15, pp561-597, (2002). http://dx.doi.org/10.1016/S0951-8339(02)00003-5.

[3] G.J. Grigoropoulos, G.M. Katsaounis: Measuring procedures for seakeeping tests of large-scaled ship models at sea. 13th IMEKO TC4 Symposium on Measurements for Research and Industrial Applications, pp135-139, (2004).

[4] C.T. Wang: Research on the experimental system for the physical simulation testing of the large scale model at sea. Master thesis, Harbin Engineering University, 2009.

[5] S.J. Shi: The research on the experimental technique of the physical simulation testing of the large scale model in real waves. Master thesis, Harbin Engineering University, 2007.

[6] F. Zhao: The research on the experimental technique of the movement performance physical simulation testing of the large scale model in real waves. Master thesis, Harbin Engineering University, 2008.

[7] T. Loukakis, G. Grigompoulos, G. Katsaounis, et al: Large scale model testing at sea. Proceedings of the 24th ITTC, Edinburgh, 2005.

[8] Final Report and Recommendations to the 25th ITTC, The Seakeeping Committee. Proceedings of the 25th ITTC Volume I, FUKUOKA, 2008.

[9] Final Report and Recommendations to the 26th ITTC, The Seakeeping Committee. Proceedings of the 26th ITTC Volume I, Rio de Janeiro, 2011.

[10] A. Coraddu, G. Dubbioso, S. Mauro, M. Viviani: Analysis of twin screw ships' asymmetric propeller behaviour by means of free running model tests. Ocean Engineering, Vol.68, pp47-64, (2013). http://dx.doi.org/10.1016/j.oceaneng.2013.04.013.

[11] S.Z. Sun, J.D. Li, X.D. Zhao, et al: Remote control and telemetry system for large-scale model test at sea. Journal of Marine Science and Application, Vol.9, no.3, pp280-285, (2010). http://dx.doi.org/10.1007/s11804-010-1008-3.

[12] S.Z. Sun, J.D. Li, X.D. Zhao: Experimental research on large scale model test in real ocean wave environment. Journal of Harbin Engineering University, Vol.30, no.5, pp475-480, (2009).

[13] S.Z. Sun, H.L. Ren, X.D. Zhao, J.D. Li: Experimental study of two large-scale models seakeeping performance in coastal waves. Brodogradnja, Vol.66, no.2, pp47-60, (2015).

[14] J.L. Jiao, H.L. Ren, S.Z. Sun, C.A. Adenya: Experimental investigation of wave-induced ship hydroelastic vibrations by large-scale model measurement in coastal waves. Shock and Vibration, Vol.2016, pp1-14, (2016). http://dx.doi.org/10.1155/2016/9296783.

[15] J.L. Jiao, H.L. Ren, S.Z. Sun, C.A. Adenya: Investigation of a ship's hydroelasticity and seakeeping performance by means of large-scale segmented self-propelling model sea trials. Journal of Zhejiang University-SCIENCE A (Applied Physics \& Engineering), Vol.17, no.4, (2016).

[16] Y.X. Yu: Random Wave and Its Applications to Engineering. Dalian. Dalian University of Technology Press, 1992.

[17] S.J. Lee, H.C. Yu, S.P. Kim, et al: Analysis of full-scale hull girder loads of a container carrier and its simulation using a nonlinear seakeeping program. Proceedings of the 29th International Conference on Ocean, Offshore and Arctic Engineering-OMAE, Vol.4, pp403-410, (2010).

[18] H.B. Luo, Q. Qiu, Z.Q. Wan, D.M. Yang: Experimental investigation of the stern slamming and whipping in regular and irregular waves. Journal of Ship mechanics, Vol.3, no.10, pp150-162, (2006).

[19] Y.S. Dai, J.W. Shen, J.Z. Song: Ship Wave Loads. National Defense Industry Press, 2007.

[20] H. Li: 3-D Hydroelasticity Analysis Method for Wave Loads of Ships. Doctoral Thesis, Harbin Engineering University, 2009.

[21] H. Li, H.L. Ren, R.M. Liu, G.Q. Feng: 3-D hydroelastic method for analysis of motion and wave loads of an FPSO ship. Journal of Harbin Engineering University, Vol.29, no.8, pp789-793, (2008).

Submitted: $\quad$ 11.06.2015.

Accepted: $\quad$ 04.03.2016.
Jialong Jiao

Shuzheng Sun, sunshuzheng@ hrbeu.edu.cn

Huilong Ren

College of Shipbuilding Engineering, Harbin Engineering

University, No.145, Nantong Street, Harbin, China 